This item was submitted to Loughborough's Research Repository by the author.

Items in Figshare are protected by copyright, with all rights reserved, unless otherwise indicated.

\title{
When humans form media and media form humans: an experimental study examining the effects different digital media have on the learning outcomes of students who have different learning styles
}

\section{PLEASE CITE THE PUBLISHED VERSION}

\section{PUBLISHER}

(C) Elsevier

\section{LICENCE}

CC BY-NC-ND 4.0

\section{REPOSITORY RECORD}

Alty, James L., A. Al-Sharrah, and N. Beacham. 2019. "When Humans Form Media and Media Form Humans: An Experimental Study Examining the Effects Different Digital Media Have on the Learning Outcomes of Students Who Have Different Learning Styles". figshare. https://hdl.handle.net/2134/3377. 
This item was submitted to Loughborough's Institutional Repository by the author and is made available under the following Creative Commons Licence conditions.

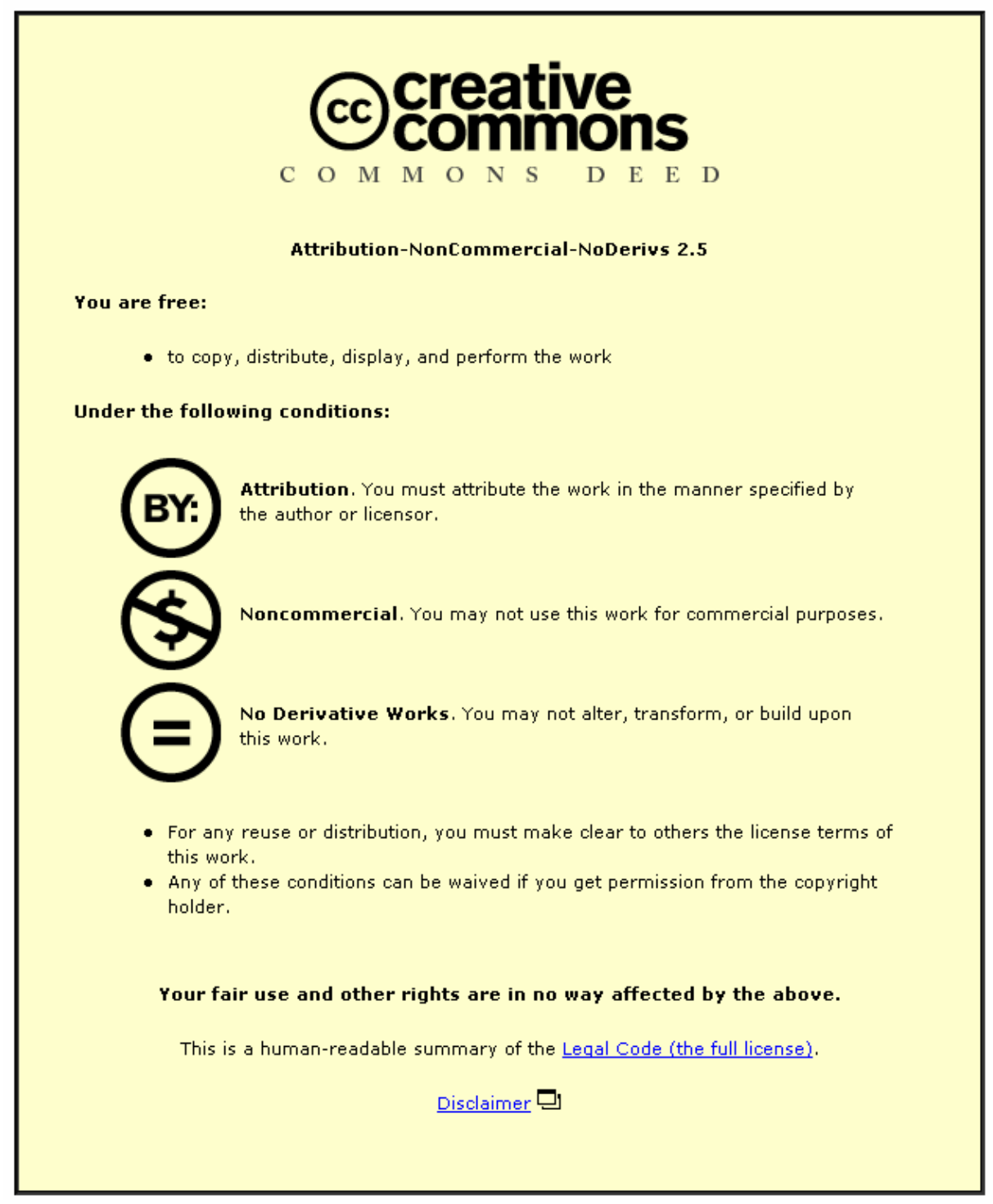

For the full text of this licence, please go to: http://creativecommons.org/licenses/by-nc-nd/2.5/ 


\title{
When Humans Form Media and Media Form Humans: An Experimental Study Examining the Effects Different Digital Media have on the Learning Outcomes of Students who have Different Learning Styles
}

\author{
J.L. Alty \\ School of Computer Science \\ Middlesex University \\ The Burroughs \\ London, NW4 4BT, UK \\ j.l.alty@mdx.ac.uk,
}

\author{
A. Al-Sharrah \\ Business College \\ Dept. of Computer Science \\ Kuwait \\ Sharrah@paaet.edu.kw \\ N. Beacham \\ Dept. of Computer Science \\ Loughborough University \\ Loughborough, Leics., \\ LE11 3TU, UK \\ N.Beacham@lboro.ac.uk
}

\begin{abstract}
A set of computer-based experiments are reported that investigate the understanding achieved by learners when studying a complex domain (statistics) in a real E-learning environment using three different media combinations - Text only, Text and Diagrams and Spoken Text and Diagrams, and the results agree with earlier work carried out on more limited domains. The work is then extended to examine how student interaction and student learning styles affect the learning outcomes. Different responses to the media combinations are observed and significant differences occur between learners classified as Sensing and Reflective learners. The experiment also identified some important differences in performance with the different media combinations by students registered as Dyslexic. The experiment was therefore repeated with a much larger sample of Dyslexic learners and the earlier effects were found to be significant. The results were surprising and may provide useful guidance for the design of material for Dyslexic students.
\end{abstract}

\section{Introduction}

Until graphical and multimedia user interfaces emerged in the 90's, the choice of digital media for representing information on a computer screen was limited to text, iconic symbols and sounds. Today, a wide choice of media are available ranging from video, animation, and sound to music, gesture and speech. Designers of computer systems are now faced, therefore, with a major problem - that of choosing the best digital media (or media combination) for a particular task, user and domain combination. They have to "form" or develop multimedia interfaces "that best match all the resources of their target learners" (Cobb, 1997, page 12) and understand how such interfaces assist in "forming" or developing understanding (or mental models, for example) in the user. Therefore, it is important for the designers of multimedia interfaces to have a clear understanding of how information that is presented in different digital media is stored, manipulated and recalled by learners.

However, different resources are often required for the same application depending on the users' goals. Users may have a variety of different task sub-goals that they wish to achieve, such as completing the task as quickly as possible, improving their understanding of what is presented, or simply enjoying the interaction, but the media 
choices that support the learning goal, for example, might actually inhibit efficiency. A task analysis approach will clarify what the user sub-goals are (Diaper and Stanton, 2004) but will not necessarily identify the most appropriate media to be used.

\section{Studies of digital media effects}

Studies into media effects using long-established technologies such as paper-based studies (Bissell et al., 1971) have encouraged subsequent research into digital media effects. These later studies have suggested that some media combinations may improve performance in tasks such as:

- Learner motivation

- Improving understanding

- Making sense of large data sets

- Reducing cognitive workload

- Providing information to users with special needs

Examples of interdisciplinary studies investigating digital media effects can be found within the literature in the areas of Psychology, Education and Computing, and within subjects such as Instructional Design, Computer-Based Learning, Human-Computer Interaction, and Cognitive and Educational Psychology (Alty, 2002; Beacham et al., 2002; Clark and Paivio, 1991; Paivio, 1986; 1991; Sadoski and Paivio, 2001; Mayer, 2001). The work has involved empirical studies on the utility of different media combinations include work on process control interfaces (Alty et al., 1993; Alty, 1999) and the effects of animation (Faraday and Sutcliffe, 1997, 1998). Such work has suggested general rules for media selection and use, but more commonly little empirical evidence is produced to substantiate decisions for selecting appropriate media (Race, 1998).

Mayer and his colleagues have carried out a number of experiments on the effects of media on learning - a summary of which can be found in Mayer (2001). Subjects were provided with material in a number of different multimedia presentations. The material presented explained for example, how a lightning storm developed, how a car's braking system worked or how a bicycle tyre pump worked. The material was presented in many different multimedia forms and the subjects' remembering, and understanding of the material, was measured in a series of tests. The results obtained gave rise to a set of design principles about multimedia design. However, Scaife and Rogers (1996), in an analysis of static and graphical representations, have argued that the absence of cognitive processing models has still resulted in a lack of practical guidelines for interface designers. A good review of the work currently in progress is given in the Handbook of Multimedia Learning (Mayer, 2005).

\section{Alternative views on media effects.}

The use of digital technologies has generated a new paradigm in our educational methodologies and strategies (Ken and Mai Neo, 2004), and some have claimed that an 
overemphasis on technology is a distraction to the main issue (Clarke, 1994). The introduction of new technologies has always led to predictions of massive effects on learning that have often not been borne out in practice. Clarke claimed that information can be represented using any number of different media and that pedagogy is the really important issue. Whilst we support the importance of pedagogy, we also support Cobb's (1997) position that digital media can still affect learning outcomes from the perspective of cognitive efficiency "Efficient instructional media systems are symbol systems that do some of the learner's cognitive work for them. It goes without saying that the most efficient medium would not necessarily be ideal for every stage of learning” (Cobb, 1997, page 11).

More recently, Narayanan and Hegarty have stressed the importance of employing a cognitive process model (Narayanan and Hegarty, 1998) when designing multi-modal material. They carried out empirical studies investigating how this could affect the learning performance of students particularly when communicating dynamic information using animation techniques (Narayanan and Hegarty, 2002). Their approach is based upon a set of design principles derived from applying the model. They found that there was no significant difference in the performance of subjects being taught using a multimodal presentation compared with the performance obtained when a paper based representation of the same model was used. The work suggests that structure and content are more important than the dynamics and interactivity offered by the multi-modal approach. However, it is important to note that their domains were that of the operation of a mechanical system and the execution of an algorithm. In each case, interactivity and animation played key roles.

\section{A cognitive theory of multimedia learning}

The Cognitive Theory of Multimedia Learning (Mayer, 2001) is based on the Dual Coding Theory of Paivio (Paivio, 1986). The theory proposes that information is processed through one of two independent channels (verbal information such as text, the spoken word and auditory events) and visual information (such as diagrams, animations and photographs). The verbal and non-verbal processing systems can function independently, though there are cross linkages between the two. Thus one would expect the recall of material to be affected by the way it is presented, so different media may be more suitable than others for allowing people to recognise, retain and recall particular types of information, and this may be further affected by individual differences.

Mayer's Theory is a compromise between Paivio’s two channel "presentation mode” approach and Baddeley’s “sensory-modality” approach (Baddeley, 1986). The former focuses on verbal and non-verbal stimuli, and the latter on processing through the eyes or ears. Schnotz has developed an integrative model of text and picture comprehension based upon a similar distinction between descriptive and depictive representations (Schnotz and Bannert, 2003).

Figure 1 (taken from Mayer 2001). The theory provides useful insights into why different combinations of media can have different effects on comprehension and learning. Mayer 
divides Sensory and Working Memory into two channels that deal with verbal and nonverbal representations and the information is presented visually or aurally, processed either by the eyes or the ears. However, once in memory, words (which may have been sensed visually) may then be converted to auditory words and processed through the auditory channel and vice-versa. Such conversions can involve additional cognitive processing.

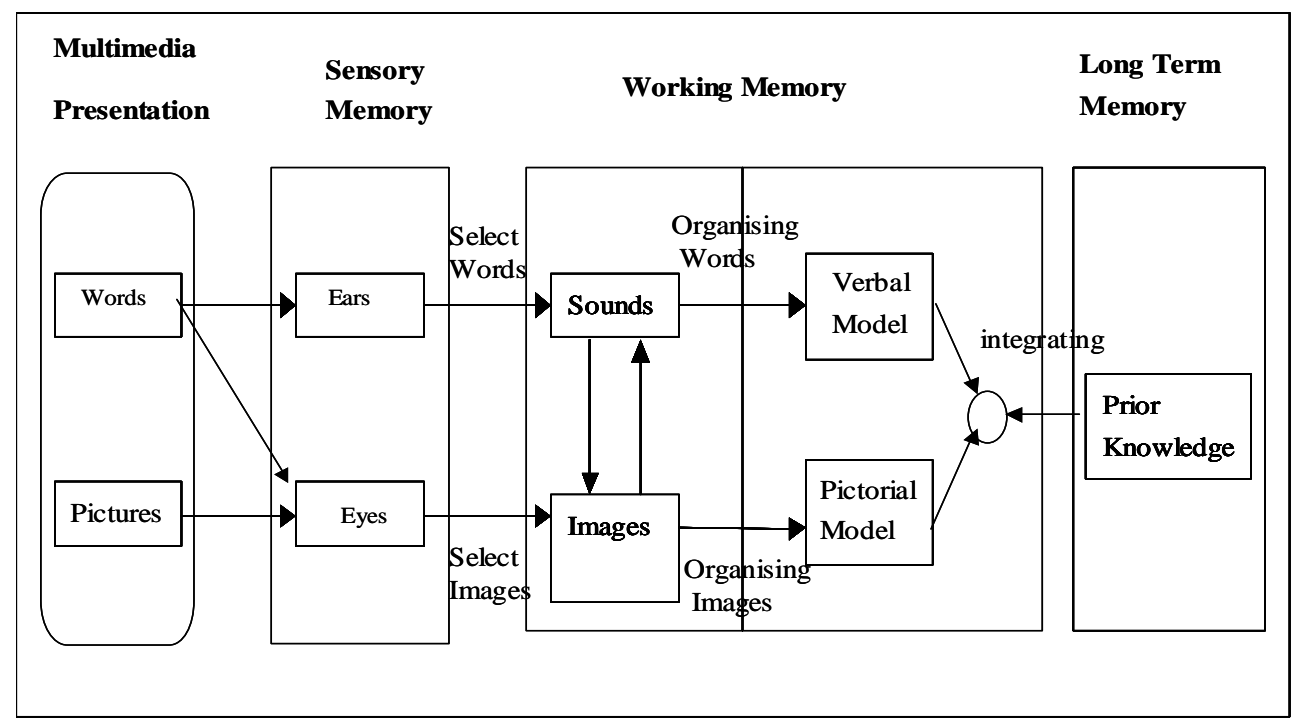

Figure 1. Mayer's Cognitive Theory of Multimedia Learning

By applying this theory to the empirical studies described above, Mayer suggested a number of multimedia design principles:

- Spatial Contiguity: Words and Pictures should be presented close together

- Temporal Contiguity: Words and Pictures should be presented simultaneously

- Coherence: Avoid unnecessary words, music and pictures

- Modality: Text is better spoken when presented with animations or pictures.

- Redundancy: The same spoken and written text when presented together can inhibit learning

- Prior Knowledge Effect: Design effects are larger for low knowledge learners than for high knowledge learners.

The Spatial Contiguity Principle has been supported by other work including that of Sweller and Chandler, (1994), and research on textbook illustrations (Mayer et al, 1995). The Coherence Principle is related to the idea of expressiveness (Alty, 1999; Williams and Alty, 1998) where it is suggested that media effects can be expressed in terms of a Signal-to-Noise ratio.

There are alternative views of memory storage that challenge Dual Coding Theory. One challenge is Propositional Theory (Rieber, 1994), which proposes that a transformation of linguistic information takes place into a semantic form of storage in long-term memory. The Propositional Theory disputes the superiority of pictures over words because people process and rehearse pictures more fully than words. However, approaches based on the 
two channel approach still seem to be useful today, in spite the advancements in new technology and changes in education (Paivio, 1991; Sadoski and Pavio, 2001).

\section{The Experimental Approach}

Earlier experiments that have examined the effects of media on learning have been constructed over relatively simple subject domains - for example, the operation of a braking system or cistern, so we decided to carry out a series of multimedia learning experiments on a much more complex domain to see how well the results would scale up. One problem with using complex domains is student motivation. If the material is complex and there is no over-riding goal to support improving learning and understanding, and it is likely that students will lose interest. A domain is required that students need as part of their studies (and therefore are motivated).

A domain within a University context that is acknowledged to be inherently difficult, and yet for many students constitutes a most desirable skill to attain, is the domain of statistics. Most masters and doctoral students require statistical knowledge for analyzing their experiments, and this sub-domain of statistics is reasonably compact. At Loughborough University, there is a Masters course on Multimedia Interface Design, and an important aspect of the course is the design and evaluation of HCI experiments using statistics. The statistics material is typically taught in four one-hour lectures on the course and covers basic information about the Null Hypothesis, the Binomial Distribution, Non-parametric tests and Normal Distributions and their use in HCI experiments. The material used in this course was therefore chosen for our experiments.

Four computer-based teaching modules (lasting between 12 and 16 minutes each) were created covering the basic statistics required for experimental analysis. The modules were: The Null Hypothesis, The Binomial Approach, The Non-parametric Approach, and Normal Distributions. These presentations had previously been given on the course using a traditional lecturing style. The four modules provide the basis for an extended and realistic test of the effects of media combinations on learning.

The material was presented in the four modules using combinations of three media - text, diagrams and the spoken voice. The three combinations chosen were - Text Only, Text + Diagrams, and Spoken Text + Diagrams. These three media were chosen so that the results could be compared with those of Mayer. Furthermore, they are typical multimedia presentation combinations used in many e-learning situations. The initial hypothesis is that students will show overall improved learning when information was presented using the Sound + Diagrams or Text + Diagrams combinations compared with a Text-Only presentation in a realistic learning situation. A second hypothesis is that student performance will vary between media combinations for modules with different content. This work differs from other work in that the domain is a complex one in a real teaching environment where the students are highly motivated. The four modules take over one hour to present and the students needed the information for the end of module examination. The students should therefore be highly motivated. 
All the three different media presentations were based upon identical material. For example, the written text and spoken text were identical. The diagrams were presented on the left hand side of the screen and the text on the right and the audio presentation used the speakers. An example screen for a Text Only presentation from Module 3 is shown in Figure 2 (though the actual screens were in colour). This illustrates how many different sums of ranks can be built up from the rankings 1 to 6 . The diagrams and the text were progressively built up, synchronized in stages. The material was constructed using Macro-Media Flash 5 (Ulrich, 2000) and each module was divided into a number of Flash scenes. The organization of the scenes was transparent to subjects, but this approach was used so that at a later date the material could be presented in a more parallel, interactive manner. In this experiment students passively watched the presentation without interaction.

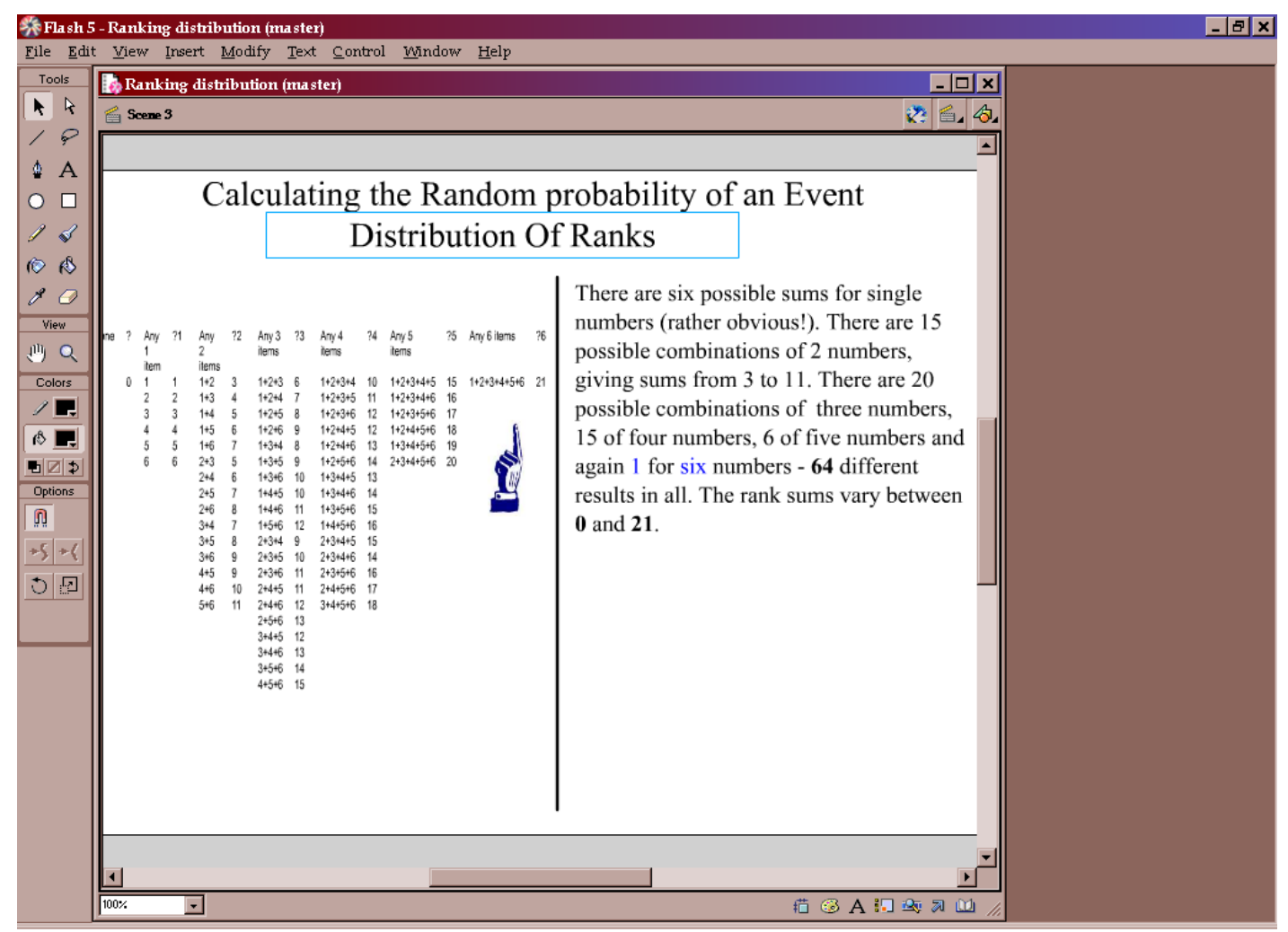

Figure 2. A Typical Screen for the Text Presentation in Module 3

Students on the M.Sc. course were all graduates and from a variety of disciplines. They were told that the four created modules would be examined at the end of the semester, but, because students would experience different styles of presentation during the experiment, there was a risk that, if presentation style really did make a difference to learning outcomes, some students might be disadvantaged in their examination depending on which presentation they used. To avoid disadvantaging students, a repeat of the presentation in a standard lecture format was given by the same tutor to all students after the conclusion of each experimental module presentation.

The text-only module was first constructed. Considerable attention was given to the structure and content of the module so that ideas were gradually introduced at a high 
level and then progressively decomposed. Then the Text + Diagrams module was designed. This required some changes to the Text-only module to keep the text identical. Finally the text was replaced by an identical verbal description. Again some modifications were required to ensure the content and structure was, as far as possible, equivalent. Extensive trials with users resulted in a number of improvements.

\section{Taking into account student learning style}

One individual difference that may be affected by media combinations is learning style, so it was decided to include a measurement of learning style in the study. Choosing a particular approach to the measurement of learning styles, however, is not simple. For example, Coffield et al (2004) have identified seventy-one learning style models and have broadly categorised them into the thirteen major models (shown in Table 1) together with their assessments of the models.

\begin{tabular}{|l|l|}
\hline Test & Assessment \\
\hline Allinson and Hayes CSI (1996) & $\begin{array}{l}\text { Best evidence of reliability and validity. Pedagogical implications } \\
\text { not fully explored. Suitable tool }\end{array}$ \\
\hline Apter (2001) & Merits further research in an educational context \\
\hline Dunn and Griggs (2003) & $\begin{array}{l}\text { Lack of independent research on the model. Forceful claims about } \\
\text { impact are questionable. }\end{array}$ \\
\hline Entwistle (1998) & Potentially useful but needs more development. \\
\hline Gregorc (1994) & Theoretically and psychometrically flawed. \\
\hline Herrmann (1989) & $\begin{array}{l}\text { Although largely ignored offers promise. Is more inclusive and } \\
\text { systematic. }\end{array}$ \\
\hline Honey and Mumford (2000) & Widely used but needs to be redesigned to address weaknesses. \\
\hline Jackson (2002) & Has promise for wider use and consequential refinement \\
\hline Kolb (1999) & Problems about reliability, validity and learning cycle \\
\hline Myers and McCaulley (1985) & Not clear which 16 elements are most relevant \\
\hline Riding and Rayner (1998) & Potential value not well served by an unreliable instrument \\
\hline Sternberg (1999) & An unnecessary addition to the many models \\
\hline Vermunt (1998) & $\begin{array}{l}\text { A rich model with potential use for post-16 education where text- } \\
\text { based learning is important. }\end{array}$ \\
\hline
\end{tabular}

Table 1. The 13 major learning style models identified by Coffield et al (2004)

Choosing the most appropriate learning style model from these seventy one models to carry out an empirical investigation into the effects of different media combinations on learning outcomes for different learning styles is not a simple task. Coffield et al. examined each major model for evidence that it could show internal consistency, test-retest reliability and construct and predictive validity. They concluded that only three of the thirteen models came close to meeting the criteria - the models of Allinson and Hayes, Apter, and Vermunt - whilst a further three of the major models - those of Entwistle, Herrmann, and Myers-Briggs - met two of the criteria.

The factors, which influenced us in deciding which particular learning style test to choose, were:

- it should be a test that can be completed in a reasonable time

- $\quad$ it should be a test that is aimed at adults (not children)

- $\quad$ it should be a test that is easy to take with minimal instruction 
- $\quad$ it should be a test that is pleasant and informative.

- $\quad$ It should be a test suitable for learning engineering and scientific material

The model adopted was that of Felder and Soloman (Felder, 1993). This model characterises learning style on four major axes - Sensing versus Intuitive, Sequential versus Global, Active versus Reflective and Visual versus Verbal learning styles. One important reason for choosing this approach was its previous use in scientific and engineering situations. Furthermore, in Coffield's classification, the Felder model is termed a "flexibly stable learning preferences" learning style, and two of the three major models which came close to meeting Coffield's consistency, reliability and validity criteria were also in this learning style family. The inventory has been independently tested and validated, and shown to produce reliable results (Zywno, 2003). The test is also easy to administer.

Since the proposed research was of an exploratory nature and the test was readily available it was decided to use it though the test has been criticised for confounding aural and symbolic modalities. Table 2 summarises some differences across the four axes of the model.

\begin{tabular}{|l|l|}
\hline \multicolumn{1}{|c|}{ One Polarity } & \multicolumn{1}{c|}{ Opposite Polarity } \\
\hline $\begin{array}{l}\text { Sensing learners - prefer facts and prefer using } \\
\text { well-known relationships. }\end{array}$ & $\begin{array}{l}\text { Intuitive learners - prefer to discover possibilities } \\
\text { and relationships }\end{array}$ \\
\hline Sequential learners - tend to learn material in steps & $\begin{array}{l}\text { Global learners - absorb material often randomly } \\
\text { without necessarily seeing the connections }\end{array}$ \\
\hline Active learners - prefer rushing in and doing & $\begin{array}{l}\text { Reflective Learners - prefer to reflect before } \\
\text { starting }\end{array}$ \\
\hline Visual learners - prefer pictures and visual material & Verbal learners - prefer written and spoken text. \\
\hline
\end{tabular}

\section{Table 2 Brief description of the different Felder learning styles.}

The position of the learner on the four Felder axes is determined by administering a test with 44 questions about attitudes. The results of the test are expressed as an odd integer (1-11) followed by the letter "a" or the letter "b" (e.g. 7a). The "a" and "b" refer to the polar styles and the integer is the strength of the tendency towards that style. Thus a 9a on the Sensing / Intuitive axis suggests a strong tendency to a Sensing style, whereas a $5 \mathrm{~b}$ would indicate a moderate tendency to an Intuitive learning style. Usually the different learning styles are spread evenly across the population as a whole. However, on the Visual/Verbal axis, there is usually a predominance of visual learners. Two example questions from the Felder test are given in Table 3. .Question 17 is concerned with Active/Reflective Learning and 20 is concerned with Sequential/Global Learning

17. When I start a homework problem, I am more likely to:

(a) start working on the solution immediately

(b) try to fully understand the problem first

20. It is more important to me to me that an instructor:

(a) lays out the material in clear logical steps

(b) gives me an overall picture and relates the material to other subjects

Table 3. Two example questions from the Felder Test. 
Before the presentation of the first module therefore, students were asked to answer the 44 questions in the Felder questionnaire to determine their learning style. The resulting distribution of learning styles over the student class is shown in Figure 3.
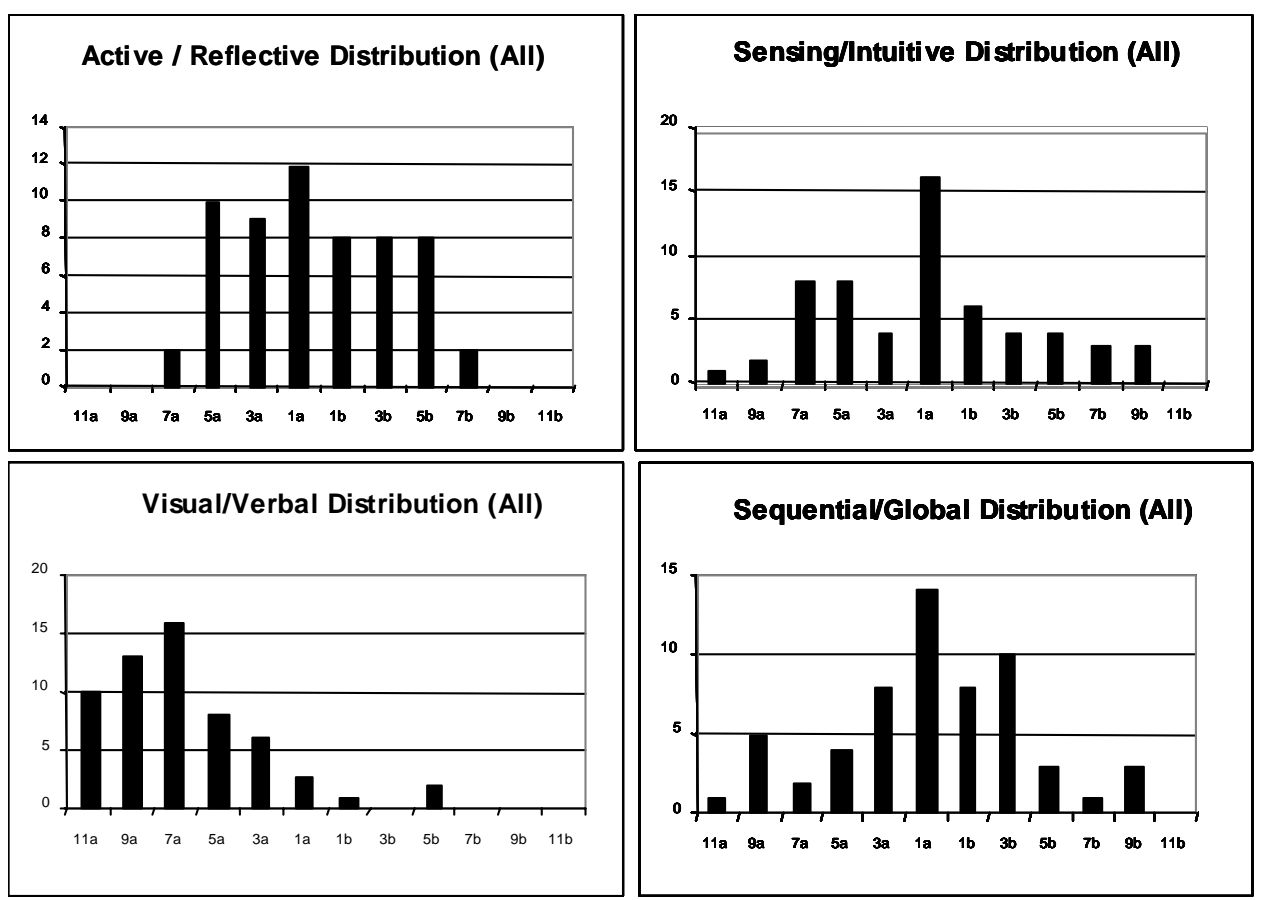

Figure 3. The distribution of learning styles across the subjects

All students really enjoyed taking this test and they were interested in their individual result. As expected, the visual style was much more common than the verbal style, so this axis was ignored in these experiments. The Visual/Verbal distribution shows the typical visual bias in the population obtained in the Felder test.

The nature of the domain did not lend itself to animation. However, ideas and diagrams were built up progressively on the screen. As new diagrammatic elements were introduced, the text would simultaneously appear on the screen or the spoken commentary would occur. Occasionally, blinking was used to emphasise elements being discussed. Colour was also used to connect important sections of text or diagrams. In this experiment the students did not interact with the presentations.

A post-test was administered after each module presentation. The post-tests for all four presentations carried 19 marks. Some typical questions are shown in Table 4. There were recall questions, recognition questions and questions that tested transfer knowledge. The experimenters independently marked the questions, and the marks awarded were almost identical in each case. Where there were disagreements these were resolved by discussion (but there were few). 
1. Some Statistical methods require the data to be transformed into a particular format. Is anything lost as a result? Can you give an example?

1. What examples were given in the lesson of one-tailed and two tailed hypotheses?

1. When we carry out an experiment and the results appear to support our hypothesis what actually might be happening?

2. Which of these are properties of the Binomial Distribution?

+ Equal chances of success and failure

+ Chance of Success $=1-$ Chance of Failure

+ Only Symmetrical Distributions

+ Fixed number of trials

3. For two conditions in an experiment we have the following differences expressed as ranks. $+1+2-3$ $+4-5-6-7$

+ What is the smallest Rank Sum?

+ What is the largest Rank Sum?

+ What Positive Sum would you expect if this was a random result?

4. Why is the Normal Distribution so important? How does it relate to the other distributions such as Ranking and Binomial?

Table 4. Typical post-test questions: the number indicates from which module the question is taken.

\section{The Results Obtained}

The students were divided into three groups (A, B, and C) with each group balanced for gender and learning styles as far as possible. Groups were then given the four modules (in the different presentation formats) as detailed below (Table 5).

\begin{tabular}{|l|l|l|l|}
\hline Presentations & Text & Text + Diagrams & Voice + Diagrams \\
\hline Null Hypothesis & Group A & Group B & Group C \\
\hline Binomial Distribution & Group B & Group C & Group A \\
\hline Ranking & Group C & Group A & Group B \\
\hline Normal Distribution & Group A & Group B & Group C \\
\hline
\end{tabular}

\section{Table 5: Groups and presentation formats}

The presentations were given on succeeding days of the course (Monday, Tuesday, Thursday and Friday) and the post-tests were conducted immediately after the presentations. As can be seen in Table 5, the groups of students were moved between the presentation formats on succeeding days to avoid biasing the results by the characteristics of any group. An analysis of the answers to previous knowledge revealed that very few students had previous knowledge of the subject area, and even some of that knowledge was incorrect. Any student who indicated that they had more than $30 \%$ previous knowledge was eliminated from the test. In fact only 1 student was eliminated on the first day and 3 on the second day. None were excluded on the third and fourth days. As a check, a full analysis was carried out ignoring previous knowledge and the results were almost identical. Altogether there were 61, 66 and 66 students in each of the three presentation types.

The most striking result was the superiority of the Sound + Diagrams presentation format over the other two. The scores achieved in the four modules are shown in Figure 4. 
A one-way ANOVA analysis on performance between the three presentation styles revealed a significant difference $(\mathrm{F}=4.612,2,190, \mathrm{p}<0.011)$. The means and standard deviations are Text Only 9.82(3.7), Text + Diagrams 9.94(4.09) and Sound + Diagrams 11.69(3.92).

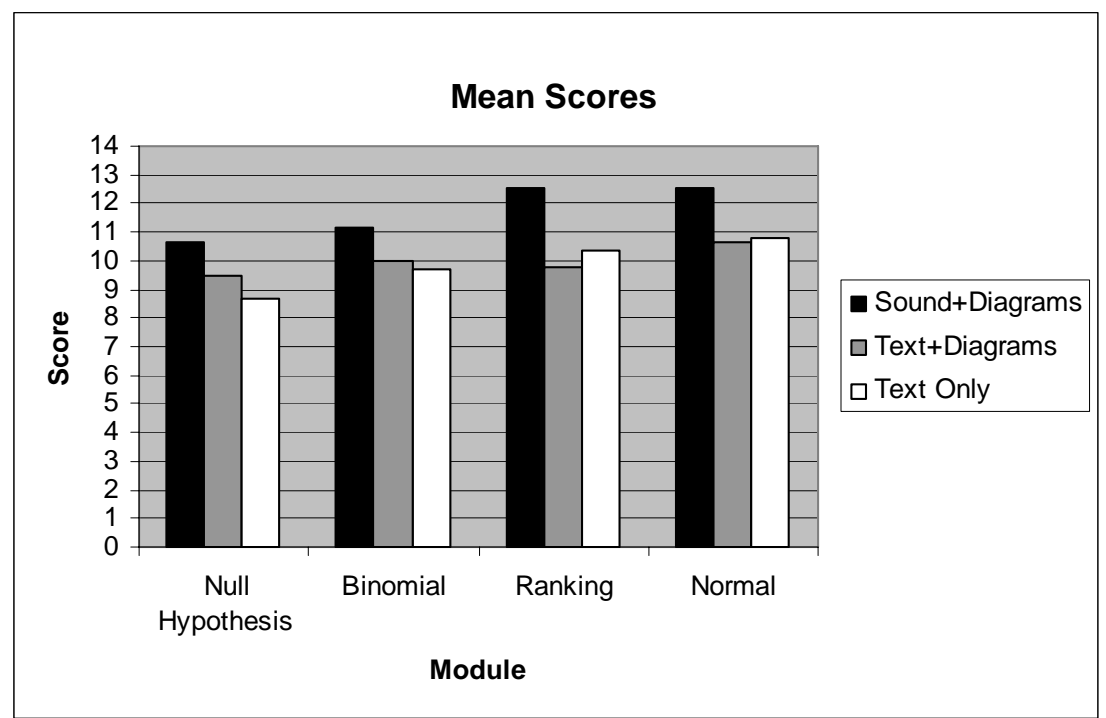

Figure 4. The knowledge test scores across the four modules

A post-hoc LSD comparison test showed the superiority of the Sound + Diagrams presentation over the other two (Table 6).

\begin{tabular}{|ll|l|}
\hline \multicolumn{2}{|l|}{ Presentation Comparison } & Significance Level \\
\hline Text Only & Text + Diagrams & 0.857 \\
& Sound + Diagrams & 0.007 \\
\hline \multirow{2}{*}{ Text + Diagrams } & Text Only & 0.857 \\
& Sound + Diagrams & 0.011 \\
\hline Sound + Diagrams & Text Only & 0.007 \\
& Text + Diagrams & 0.011 \\
\hline
\end{tabular}

Table 6 LSD Post Hoc comparison between the three presentations.

Furthermore, the effect persists across the different module contents even though the nature of the content varied considerably. For example, the first module (Null Hypothesis) is very descriptive, whereas the Binomial and Ranking modules are more mathematical in nature. Although scores generally increase over the four days there was no appreciable learning effect. The means and standard deviations for the total score for each module over the four days are 9.60(4.71), 10.18(3.43), 10.79(3.7) and 11.41 (3.52). An analysis of variance indicates no significant performance difference over the four days $(\mathrm{F}=1.915,3,189, \mathrm{p}<0.129)$. A Post Hoc LSD comparison indicated that there was a significance level of $\mathrm{p}<0.024$ between days 1 and 4 but this may be due to the nature of the material presented on day 4 compared with day 1 rather than a learning effect.

The results agree with those of Mayer (2001). A similar improved performance for the Sound + Diagrams presentation is observed as with Mayer's Sound + Pictures presentation. The similarity in performance between Text +Diagrams and Text Only 
surprised us. Dual Coding Theory (and Mayer's results) predicts that the former will be more effective. We suspect that the way in which the material was presented affected this result. Text was placed on one side of the screen and the Diagrams on the other (see Figure 2). This violates Mayer's Spatial Contiguity principle and probably results in additional cognitive processing. It is likely that the Text + Diagrams presentation would have been better than Text-only if this had been done.

An analysis was carried out to determine if the participants' learning style had an effect on learning. There were no clear effects for Global versus Sequential learners, or for Active versus Reflective learners. However, there were interesting differences for Sensing versus Intuitive learners. The results for this group are shown in Figure 5. The dependent variable, mean score, is the same as used for the previous analysis.

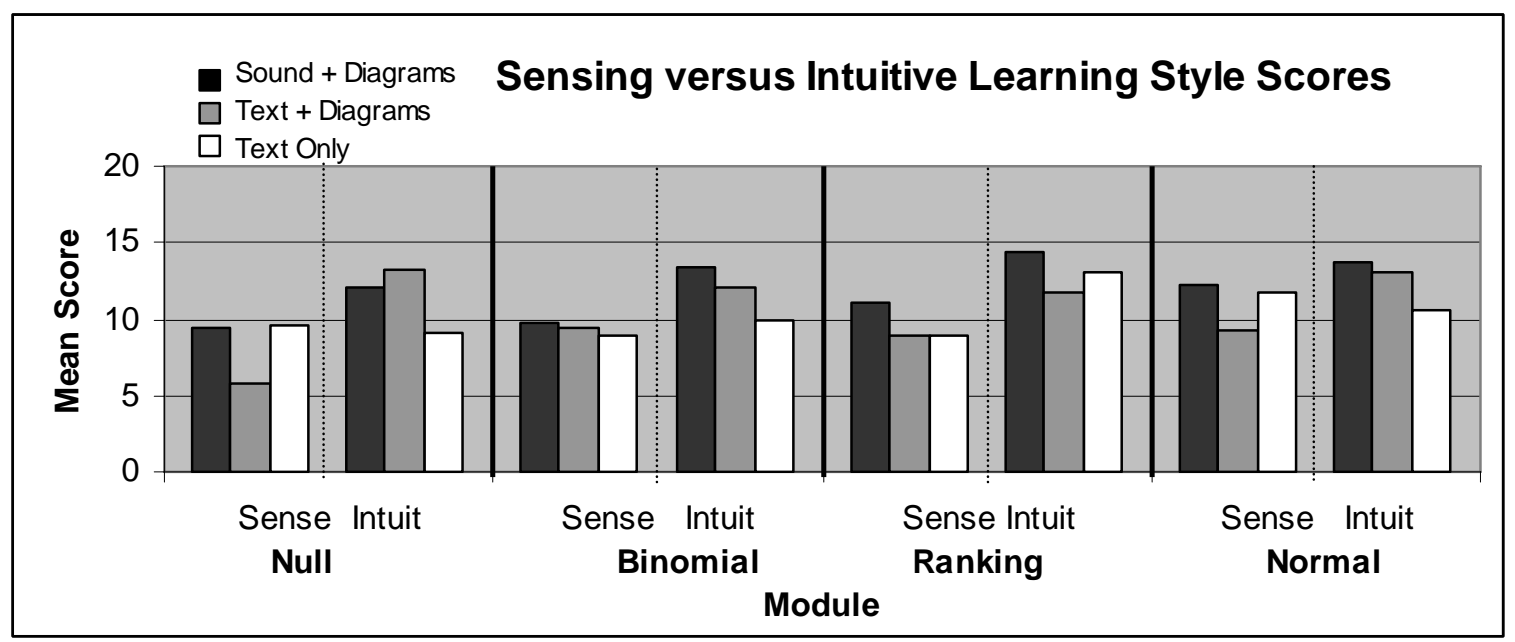

Figure 5. The performance of Sensing and Intuitive learners

A 2X3 ANOVA analysis with presentation and learning style as factors yielded the results displayed in Table 7 and 8.

Dependent Variable: score

\begin{tabular}{|l|l|r|r|r|}
\hline present & Sens/int & \multicolumn{1}{c|}{ Mean } & Std. Deviation & $\mathrm{N}$ \\
\hline Text Only & Sens & 9.31 & 3.623 & 45 \\
& Int & 10.90 & 3.714 & 21 \\
& Total & 9.82 & 3.700 & 66 \\
Text+Diag & Sens & 8.80 & 3.816 & 46 \\
& Int & 12.55 & 3.546 & 20 \\
& Total & 9.94 & 4.095 & 66 \\
Sound+Diag & Sens & 11.09 & 3.569 & 44 \\
& Int & 13.24 & 3.882 & 17 \\
& Total & 11.69 & 3.753 & 61 \\
Total & Sens & 9.72 & 3.775 & 135 \\
& Int & 12.16 & 3.773 & 58 \\
& Total & 10.45 & 3.928 & 193 \\
\hline
\end{tabular}

Table 7. Descriptive Statistics for Sensing and Intuitive Learners 
In all cases the means are higher for Intuitive Learners, though less marked for the Text Only case. The standard deviations are well within a factor of two and Levene's test for equality of error variances yielded a significance factor of $\mathrm{p}<0.973$ showing that the error variance was equal across groups.

Dependent Variable: score

\begin{tabular}{|l|r|r|r|r|r|}
\hline Source & $\begin{array}{c}\text { Type III Sum } \\
\text { of Squares }\end{array}$ & df & Mean Square & \multicolumn{1}{c|}{ F } & \multicolumn{1}{c|}{ Sig. } \\
\hline Corrected Model & $425.444(\mathrm{a})$ & 5 & 85.089 & 6.273 & .000 \\
Intercept & 19460.921 & 1 & 19460.921 & 1434.821 & .000 \\
present & 116.847 & 2 & 58.423 & 4.307 & .015 \\
sensint & 250.998 & 1 & 250.998 & 18.506 & .000 \\
present * sensint & 34.942 & 2 & 17.471 & 1.288 & .278 \\
Error & 2536.338 & 187 & 13.563 & & \\
Total & 24041.000 & 193 & & & \\
Corrected Total & 2961.782 & 192 & & & \\
a R Squared = 144 (Adjusted R Squared = 121)
\end{tabular}

Table 8. 2x3 ANOVA results for Sensing and Intuitive Learners

The Analysis of variance shows a highly significant effect between Sensing and Intuitive learners $(\mathrm{F}=18.506,1,187, \mathrm{p}<0.0001)$, but interestingly no interaction effect between Presentation and Learning style.

A 2x4 analysis of variance yielded the following results for performance over the four modules. There is a highly significant difference in the performance of Sensing and Intuitive learners over the four modules $(\mathrm{F}=17.525,1,185, \mathrm{p}<0.0001)$. There is no significant difference in the performance in the individual modules $(F=1.729,3,185$, $\mathrm{p}<0.163)$ and there is no significant interaction effect $(\mathrm{F}=2.3462,3,185, \mathrm{p}<0.918$

It is not completely clear why the Intuitive style learners performed better overall. It is not due to the type of presentation nor the information in each module. However, the content of the four modules is more theoretical than practical and this might explain the result. Perhaps then theoretical nature of the material favoured the Intuitive learners. We are planning a much more practically orientated learning experiment involving the replacement of components of a computer. This will hopefully benefit Sensing Learners. More carefully designed experiments are needed in which the tasks and media chosen more closely match the learning style characteristics.

\section{The Effects of Student Dyslexia.}

In the study described in section 7, there were six registered Dyslexic students and we were able to examine the difference in scores in the post-test between Dyslexic students and non-Dyslexic students. Although the sample was too small to achieve significance the experimental results suggested that computer-based media combinations might affect learners who have Dyslexia differently to non-Dyslexic learners. This was unexpected, since the learning materials used involve both verbal and nonverbal content. 
The experiment was therefore repeated with 30 Dyslexic students from Loughborough University. The participants were taken from various courses taught at the University and all volunteered for the study. Participants were mainly from Science departments (10), and Engineering departments (12), but there were 8 students from Arts departments. The participants completed a number of cognitive assessments using the Lucid Adult Dyslexia Screening software (LADS, 2000) and a Visual Perceptual Problems Inventory (VPPI). Whilst each participant was being assessed, the participant's data from the Learning Style test was analysed and used to place him or her in one of three groups according to his or her Sensing/Intuitive learning style. As far as possible, each group was also balanced according to gender and learning styles.

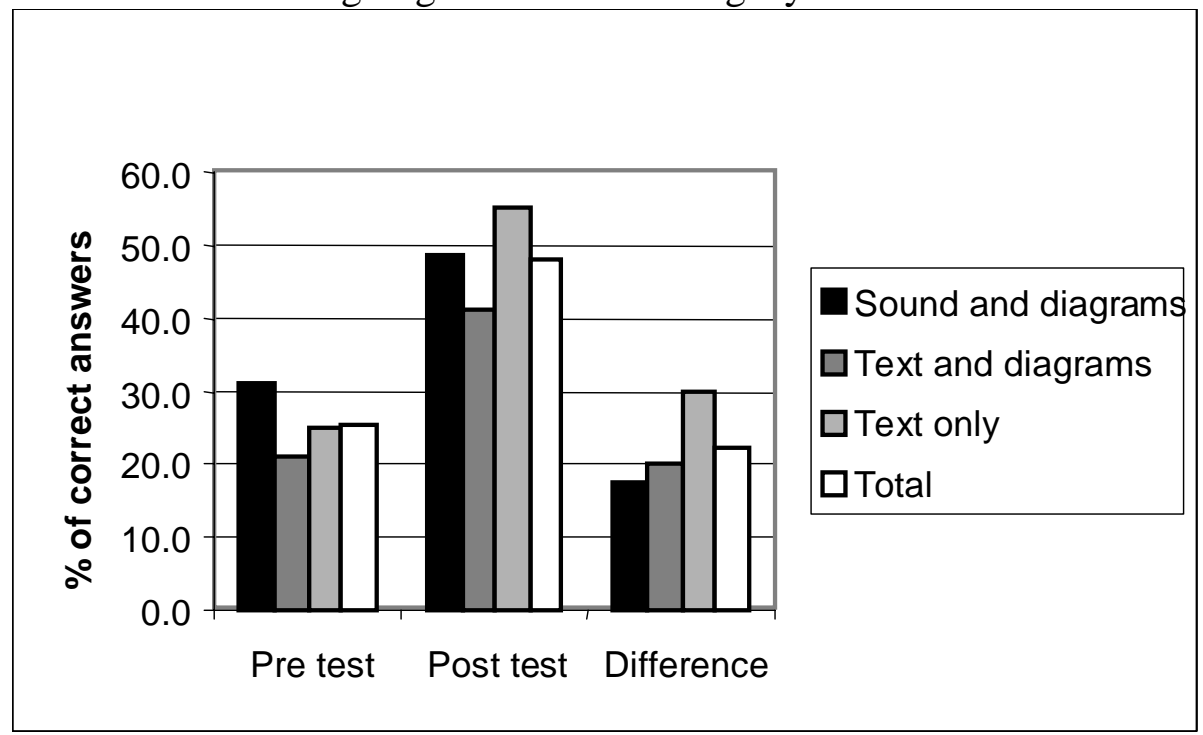

Figure 6. The pre- and post- test results for Dyslexic students

Because of the different backgrounds of the students in this experiment each participant was given a pre-test. The three groups were then were presented with the material from the first module (The Null Hypothesis module) in the three different media combinations - sound and diagrams, text and diagrams, and text alone. Then after seeing the presentation, each participant was given a post-test. The results are shown in Figure 6. A one-way ANOVA analysis showed that the difference was highly significant ( $F=3.735,2$, $27, \mathrm{p}<0.037)$ and a post hoc analysis LSD test showed significant differences between Text Only and both Sound + Diagrams $(\mathrm{p}<0.016)$ and Text and Diagrams $(\mathrm{p}<0.049)$ the Text Only having better learning scores. If this is compared with the earlier results (the first part of figure 4) it is interesting that the Dyslexic students responded quite differently to Non-Dyslexic students.

Interestingly, the analysis of the performance of the Dyslexic learners in relation to learning styles produced different results than the previously reported experiment. In this case the media differences produced significant results for Active, Sensing, Visual or Global Learners $(\mathrm{p}<0.031, \mathrm{p}<0.002, \mathrm{p}<0.015, \mathrm{p}<0.04)$ but not for Reflective, Intuitive or Sequential learners (a full report of the experiment is given in Beacham and Alty, 2006). 
It should be noted that the Dyslexic students came from a wider population than the students in the previous experiment. The students in the former experiment were all computer literate students who had an interest in Computer Science. In the Dyslexic student group two thirds of the subjects were Scientists or Engineers, one third of the students came from Art and Design, Social Sciences and Business Studies. This perhaps may have affected the result and needs further study.

The results from the study suggest that the combinations of media affected the understanding achieved by Dyslexic and non-Dyslexic students in different ways. For example, the media combination Sound + Diagrams gave significant performance difference for non-Dyslexic students, but not for Dyslexic students. In contrast, Text-only presentations had the opposite result - Dyslexic students performing better with this media than with the other combinations. The superior performance with the Text-only presentation for Dyslexic students was surprising and contrary to what might have been expected, since Dyslexic students are usually thought to have difficulties with textual presentations. It is possible that this difference might be due to the development of compensating strategies for handling text.

These findings also broadly agree with the ideas associated with Dual Coding Theory (Paivio and Begg, 1981; Paivio, 1991; Sadoski and Paivio, 2001). Paivio reported that whilst in general using text and diagrams is more effective than text alone in conveying information, because of individual differences there are cases where this may not prove true. However, Paivio was unable to provide a clear explanation for this in terms of Dyslexic learners.

It is likely that that the e-learning materials used in this study placed different cognitive demands on the Dyslexic learners compared to the cognitive demands on non-Dyslexic learners in the original study. This resulted in Dyslexic learners recalling more information when presented with text alone. The media combinations may have exacerbated the difficulties that Dyslexic learners experience due to their different level of cognitive skills, learning style preferences, competence and experience. The sound and diagrams presentation may have assisted in the retention of non-verbal information but resulted in little retention of the verbal information. The presentation containing text and diagrams may have resulted in little retention of the visual verbal and nonverbal information because of a split-attention effect (Sweller et al, 1998). The effect may exacerbate the difficulties Dyslexic learners experience due to their skills being less fluent, more demanding and more error prone (Peer, 2003).

\section{Conclusions}

The initial experiments replicated the effects observed by Mayer and his colleagues. However, the domain of learning used was a more complex domain - that of Statistics applied to Null Hypothesis testing, and the students were highly motivated. The experiment has now been carried out three times (on large numbers of students) and in each case the Sound + Diagrams media combination significantly outperforms the Text + Diagrams and the Text-only presentations. Dual Coding Theory suggests that a difference ought to have observed between the Text + Diagrams and Text-only presentations but 
performance was actually very similar. We suspect this was because our design introduced a "split attention" effect from the Text and Diagrams being physically separated on the page. This required increased cognitive effort by the learner and reduced the Text + Diagrams effectiveness. In future experiments we will endeavour to eliminate this effect.

The results differ from those of Narayanan and Hegarty in that significant differences were observed between the different media combinations. We suspect that the nature of the domain and the lack of interactivity contributed to this difference. There was no animation in our presentations, and the progressive explanation of the nature and use of statistics is very different from explaining a mechanical operation (where animation is usually highly relevant). An experiment that uses media combinations to guide the replacement of components in a computer, where the effects of Narayanan and Hegarty might be observed, is now being planned.

The second set of experiments showed that there was a significant effect of one of the student learning styles - Sensing verses Intuitive learning - though no significant differences were observed on the other two axes (Sequential versus Global or Active versus Reflective). It is not obvious why this difference was observed and this requires further study perhaps by using a more sensitive Learning Style test. It is likely to be related both to the nature of material presented (practical examples versus theory) but the media used may also have an effect. For example, the use of video material (not used in our experiments) might favour Sensing learners over Intuitive learners, as would a very practical task. On the other hand, a learning situation where theory was heavily used is likely to favour Intuitive learners. The effects of different media combinations on learning in practical tasks (such as changing components in a computer) might yield interesting learning style differences.

One of the most interesting effects found in the study was the very different response to media combinations of Dyslexic students, initially observed in the first experiment, but replicated in the special study which concentrated on Dyslexic student subjects only. The experiment suggested that different computer-based media combinations affected learners who have Dyslexia differently to non-Dyslexic learners. This was unexpected, since the learning materials used consisted of both verbal and nonverbal content. Whilst we would have expected the Dyslexic subjects to have problems with text alone, it was not expected they would have problems with text and diagrams or with sound and diagrams. Interestingly, some Dyslexic subjects obtained higher scores when having information presented as text alone than with text and diagrams.

The findings from the study also suggest that information presented using text and diagrams for non-Dyslexic learners may not be the most efficient way of presenting information to Dyslexic learners. Furthermore, the results could not be completely explained by Dual Coding Theory (Paivio and Begg, 1981). It is possible that the different media combinations put different cognitive loads on the Dyslexic students compared with non-Dyslexic students. Perhaps the Text-only presentation facilitated Dyslexic coping strategies. Interestingly, the presentation style we thought might have given the best results (Text and Diagrams) actually resulted in the worst performance. For 
a more detailed analysis of these results for Dyslexic students, see Beacham and Alty, 2006.

Findings from the study have raised a number of new and important issues. Firstly, how might computer-based media affect Dyslexic learners differently to non-Dyslexic learners, and secondly, should e-learning materials be designed specifically for Dyslexic students? The study suggests that that varying the combinations of computer-based media affects the learning outcomes of Dyslexic students in a different way to those of nonDyslexic students implying that serious consideration needs to be given as to the way e learning materials are designed and delivered.

\section{References}

Allinson, C., and Hayes, J., (1996), The Cognitive Styles Index, Journal of Management Studies, Vol. 33, $119-135$.

Alty J.L., Bergan, M., Craufurd, P., and Dolphin, C., (1993), Multimedia and process control: Some initial experimental results, Computers and Graphics, Vol. 17, No 3, 205 - 218. Alty, J.L., (1999), Multimedia and process control: Signals or noise? Transactions of the Institute of Measurement and Control, Vol. 21, No. 4/5, 181 - 190.

Alty, J.L., (2002), Dual Coding Theory and education: Some media experiments to examine the effects of different media on learning, In Proc. Ed-MEDIA: World Conference on Educational Multimedia and Telecommunications, Denver, Colorado, USA, $42-47$.

Apter, M.J., (2001), Motivation styles in everyday life: a guide to reversal theory, American Psychological Association, Washington DC., USA.

Baddeley, A., (1986), Working Memory, Clarendon Press, Oxford, England.

Beacham, N., Elliott, A., Alty, J.L., and Al-Sharrah, A., (2002), Media combinations and learning styles: A Dual Coding Theory approach, In Proc. of ED-MEDIA: World Conference on Educational Multimedia, Hypermedia and Telecommunications, Denver, Colorado, 111 - 116.

Beacham N.A., and Alty, J.L., (2006), An Investigation into the effects that digital media can have on the learning outcomes of individuals who have Dyslexia, Computers and Education Journal, Vol. 41, No.1, 74 - 93.

Bissell, J., White, S., and Zivin, G., (1971), Sensory modalities in children's learning, Psychology and Educational practice, Lesser, G.S., (ed.), Scott, Foresman and company: London, 130-155.

Clark, J.M., and Paivio, A., (1991), Dual Coding Theory and Education, Educational Psychology Review, Vol. 3, 149 - 210.

Clarke, R.E., (1994), Media will never influence learning, Educational Technology

Research Development, Vol. 42, No. 2, 21 - 29.

Cobb, T., (1997), Cognitive efficiency: Towards a revised theory of media, Educational Technology Research and Development, Vol 45, No. 4, 21 - 35.

Coffield, F., Moseley, D., Hall, E., and Ecclestone, K., (2004), Should we be using Learning Styles? What research has to say in practice. Report of the Learning and Skills Development Agency, Regent Arcade House, Argyle St., London.

Diaper, D., and Stanton, N.A., (2004), The Handbook of Task Analysis for Human 
Computer Interaction, Lawrence Erlbaum Associates, Mahwah, N.J.

Dunn R., and Griggs, S., (2003), Synthesis of the Dunn and Dunn learning styles model research: who, what, when, where and so what - the Dunn and Dunn learning styles model and its theoretical cornerstone, St. Johns University, New York, USA.

Entwistle, N.J., (1998), Improving teaching through research on student learning, In University Teaching: International perspectives, Forrest, J.J.F., (ed.), Garland, N.Y.

Faraday, P.M., and Sutcliffe, A.G., (1997), Multimedia: Design for the moment, In Proc. Multimedia'97, ACM, 183 - 193.

Faraday, P.M., and Sutcliffe, A.G., (1998), Providing advice for multimedia designers. In Proc. CHI'98, ACM, 124 - 131.

Felder, R., (1993), Reaching the second tier: Learning and teaching styles in college science education, Journal of College Science Teaching, 23, 286 - 290.

Gregorc, A.F., (1984), Style as a symptom: a phenomenological perspective, Theory and Practice, Vol. 23 (1), 51 - 55.

Herrmann, N., (1989), The creative brain: Brain Books, The Ned Herrmann Group, North Carolina, USA.

Honey, P., and Mumford, A., (2000), The learning styles helpers guide, Peter Honey Publications Ltd., Maidenhead, UK.

Jackson, C., (2002), Manual of the learning styles profiler, www.psi-press.co.uk

Ken Neo and Mai Neo, (2002), Building a constructivist learning environment using a multimedia design project - a Malaysian experience, Journal of Multimedia and Hypermedia, Vol. 11, No. 2, 141 - 153.

Kolb, D.A., (1999), The Kolb learning style inventory: version 3, Hay Group. Boston. LADS, (2002). Lucid Adult Dyslexia Screening Administrator's Manual, Version 1.0, C. Singleton, K. Thomas (eds.).

Mayer, R.E., Sims, V., and Tajika, H., (1995). For whom is a picture worth a thousand words? Extensions of a Dual Coding Theory of multimedia learning. Journal of Educational Psychology, 84, 389-401.

Mayer, R.E., (2001). Multimedia learning. Cambridge University Press, Cambridge, UK. Mayer, R.E., (2005), The Cambridge Handbook of Multimedia Learning, Mayer, R.E., ed., Cambridge University Press, Cambridge.

Myers, I.B., and McCaulley, M.H., (1985), Manual: A guide to the development and use of the Myers-Briggs Type indicator, Consulting Psychologists Press, Palo Alto, CA. Narayanan, N.H., and Hegarty, M., (1998), On designing comprehensible interactive hypermedia manuals, Int. J. Human-Computer Studies, Vol. 48, 267 -301.

Narayanan, N.H., and Hegarty, M., (2002), Multimedia design for communication of dynamic information, Int. J. Human-Computer Studies, Vol. 57, 279 - 315.

Paivio, A., (1986) Mental Representations: A Dual Coding Approach. New York: Oxford University Press.

Paivio, A., (1991). Dual Coding Theory: Retrospect and current status. Canadian Journal of Psychology, 45, 255-287.

Paivio, A. \& Begg, I. (1981). Psychology of language. Prentice-Hall: London, UK. Peer, L., (2003). Ethnic minority learners with dyslexia. British Dyslexia Association Series of Termly Papers, January.

Race, P., (1988), 500 Tips for Open and Flexible Learning, Kogan Page, London 
Riding , R., and Rayner, S., (1998), Cognitive styles and learning strategies: understanding style differences in learning behaviour, David Fulton, London, UK. Rieber, L.P., (1994). Computers, graphics and learning. Madison. WI: WCB Brown \& Benchmark.

Sadoski, M., and Pavio, A., (2001) Imagery and text: A Dual Coding Theory of reading and writing, Lawrence Erlbaum Associates, Inc.

Scaife, M., and Rogers, Y., (1996), External Cognition: how do graphical representations work? Int. J. of Human-Computer Studies, Vol. 45, 185 - 213.

Schnotz, W., \& Bannert M., (2003). Construction and Interference in Learning from Multiple Representations, Learning and Instruction, Vol. 13, 141 - 156

Sweller, J., and Chandler, P., (1994). Why some material is difficult to learn. Cognition and Instruction, 12, 185-233.

Sweller, J., van Merrienboer, J.J.G., \& Paas, F.G.W.C., (1998). Cognitive architecture and instructional design. Educational Psychology Review, 10(3), 251-296.

Ulrich, K., (2000). Flash 5 for Windows and Macintosh: Visual Quick Start Guide, $3^{\text {rd }}$ Edition, Peachpit Press.

Williams, D.M.L., and Alty, J.L., (1998), Expressiveness and multimedia interface design, Proc. of Edmedia-98, Ottman, T., and Tomek, I. (eds.), Freiburg, Germany, pp 1505 -1510. Vermunt, J.D., (1998), The regulation of constructive learning processes, British Journal of Educational Psychology, Vol. 68, 149 - 171.

Zywno, M.S. (2003). A Contribution to Validation of Score Meaning for FelderSoloman's Index of Learning Styles, Session 2351, In the proceedings of the 2003 ASEE Annual Conference and Exposition, Nashville, Tennessee, June 23-25, 2003. Available online at: http://www.ncsu.edu/felderpublic/ILSdir/Zywno_Validation_Study.pdf 